\title{
Regulation of glucose metabolism by p53: Emerging new roles for the tumor suppressor
}

\author{
Esha Madan'1,2, Rajan Gogna², Madan Bhatt³, Uttam Pati², Periannan Kuppusamy4, \\ Abbas Ali Mahdi ${ }^{1}$ \\ 1 Department of Biochemistry, Chhatrapati Shahuji Maharaj Medical University, Lucknow, India \\ ${ }^{2}$ Transcription and Human Biology Laboratory, School of Biotechnology, Jawaharlal Nehru University, New-Delhi, India \\ ${ }^{3}$ Department of Radiotherapy and Chemotherapy, Chhatrapati Shahuji Maharaj Medical University, Lucknow, India \\ ${ }^{4}$ Dorothy M. Davis Heart and Lung Research Institute, Dept. of Internal Medicine, Ohio State University, Columbus, OH, USA \\ Correspondence to: Abbas Ali Mahdi PhD, email: mahdiaa@rediffmail.com
}

Keywords: p53, Metabolism, TIGAR, SCO2, Tumor Suppressor

Received: December 19,2011, Accepted: December 20, 2011, Published: December 31, 2011

Copyright: ( Madan et al. This is an open-access article distributed under the terms of the Creative Commons Attribution License, which permits unrestricted use, distribution, and reproduction in any medium, provided the original author and source are credited.

ABSTRACT:

p53 is well known as the "guardian of the genome" for differentiated and neoplastic cells. p53 induces cell-cycle arrest and cell death after DNA damage and thus contributes to the maintenance of genomic stability. In addition to this tumor suppressor function for pro-oncogenic cells, p53 also plays an important role as the central regulator of stress response by maintaining cellular homeostasis at the molecular and biochemical level. p53 regulates aerobic respiration at the glycolytic and oxidative phosphorylation (OXPHOS) steps via transcriptional regulation of its downstream genes TP53-induced glycolysis regulator (TIGAR) and synthesis of cytochrome c oxidase (SCO2). p53 negatively regulates glycolysis through activation of TIGAR (an inhibitor of the fructose-2,6-bisphosphate). On the contrary p53 positively regulates OXPHOS through upregulation of $\mathrm{SCO}$, a member of the COX-2 assembly involved in the electron-transport chain. It is interesting to notice that p53 antagonistically regulates the inter-dependent glycolytic and OXPHOS cycles. It is important to understand whether the p53-mediated transcriptional regulation of TIGAR and SCO2 is temporally segregated in cancer cells and what is the relation between these paradoxical regulations of glycolytic pathway with the tumor suppressor activity of p53. In this review we will elucidate the importance of p53-mediated regulation of glycolysis and OXPHOS and its relation with the tumor suppressor function of p53. Further since cellular metabolism shares great relation with the process of aging we will also try and establish the role of p53 in regulation of aging via its transcriptional control of cellular metabolism.

\section{ABSTRACT}

p53 is well known as the "guardian of the genome" for differentiated and neoplastic cells. p53 induces cellcycle arrest and cell death after DNA damage and thus contributes to the maintenance of genomic stability. In addition to this tumor suppressor function for prooncogenic cells, p53 also plays an important role as the central regulator of stress response by maintaining cellular homeostasis at the molecular and biochemical level. p53 regulates aerobic respiration at the glycolytic and oxidative phosphorylation (OXPHOS) steps via transcriptional regulation of its downstream genes TP53induced glycolysis regulator (TIGAR) and synthesis of cytochrome $c$ oxidase (SCO2). p53 negatively regulates glycolysis through activation of TIGAR (an inhibitor of the fructose-2,6-bisphosphate). On the contrary p53 positively regulates OXPHOS through upregulation of $\mathrm{SCO} 2$, a member of the COX-2 assembly involved in the electron-transport chain. It is interesting to notice that $\mathrm{p} 53$ antagonistically regulates the inter-dependent glycolytic and OXPHOS cycles. It is important to understand 
whether the p53-mediated transcriptional regulation of TIGAR and SCO2 is temporally segregated in cancer cells and what is the relation between these paradoxical regulations of glycolytic pathway with the tumor suppressor activity of p53. In this review we will elucidate the importance of p53-mediated regulation of glycolysis and OXPHOS and its relation with the tumor suppressor function of p53. Further since cellular metabolism shares great relation with the process of aging we will also try and establish the role of p53 in regulation of aging via its transcriptional control of cellular metabolism.

\section{INTRODUCTION}

$p 53$, often referred to as the "guardian of the genome," is the most commonly mutated gene in human cancer [1]. In response to DNA damage or other types of stress, p53 acts as a sequence-specific transcription factor and orchestrates the appropriate cellular response by inducing cell-cycle arrest, apoptosis, senescence, or differentiation $[2,3]$. Thus p53 mediates cell response to various cellular stressors and thus plays a pivotal role in tumorogenesis, cell-death and survival [4]. In cells experiencing DNA-damage, hypoxia, genotoxicity, cytotoxicity, and oxidative stress, p53 dissociates from its ubiquitin ligase MDM2, via various post-translational modifications which promote its stabilization and activation [5]. Active p53 migrates to the nucleus and activates the expression of its down-stream genes involved in cell-cycle regulation, DNA repair, senescence, and cell death [1]. Recent findings indicated that p53 plays an important role in the regulation of cellular metabolism, specifically glycolysis and OXPHOS in cancerous cells. Glucose metabolism is a major step in the development and sustenance of a variety of cancers in human body. However, how p53 regulates metabolism and the relation of this newly discovered role of p53 with its universal role of tumor suppressor is not known. The regulation of cellular metabolism determines the physiological response of cancer cells to nutrients and oxygen and accordingly chooses to promote cell-proliferation, growth and survival [6]. In this review, we will try to elucidate the complex network of p53 regulation of cellular metabolism and p53 tumor suppressor activity.

\section{P53 AND THE WARBURG EFFECT}

Otto Warburg established that cancer cells undergo high rates of aerobic glycolysis due to lack of mitochondrial oxidative phosphorylation [7, 8]. This effect termed as the "Warburg effect" is one of the prime causes of malignancy. The cellular metabolism in cancer cells is dependent upon key cancer-related transcription factors, such as p53 and HIF-1 [8, 9]. p53 is now known to positively upregulate OXPHOS by transcribing $\mathrm{SCO} 2$ (a COX2 assembly protein) and p53 down-regulates glycolysis by transcribing TIGAR (an inhibitor of the fructose-2,6-bisphosphate) [8-11]. Recent research shows that loss of p53 enhances aerobic glycolysis in cancer cells, resulting in the development of a more aggressive and highly metastatic forms of cancer [12]. Most of the cancer forms are linked with a physiological phenomenon termed "hypoxia", thus expression of HIF-1 plays an important part in the regulation of cancer-cell metabolism [13]. HIF1 directly influences Warburg effect by transcriptional regulation of glycolytic enzymes such as HK2, PDK1, and LDH-A $[8,14]$. Considering the importance of p53 in tumor suppression and the high mutation rate of p53 $(>50 \%)$ in human tumors, recent findings suggest that the mutation of the p53 gene and the resultant loss of function of the p53 protein in tumors could be an important genetic change contributing to the Warburg effect.

\section{ROLE OF P53 IN REGULATING GLYCOLYSIS}

p53 is now known to not only drive the damaged cells to undergo apoptosis but also coordinates how cells use nutrients to preserve their survival. The role of p53 in the negative regulation of cellular glycolysis is now reported [15]. The p53 downstream gene TIGAR (TP53-induced glycolysis and apoptosis regulator), is a direct transcriptional target of p53 and it alters the pathway in which cancer cells use cellular glucose. TIGAR shares functional sequence similarities with the bis-phosphatase domain (FBPase-2) of the bi-functional enzyme PFK-2/FBPase-2 (6-phosphofructo-2-kinase/ fructose-2,6-bisphosphatase), which degrades fructose2,6-bisphosphate (Fru-2,6- $\mathrm{P}_{2}$ ). Fru-2,6- $\mathrm{P}_{2}$ induces 6-phospho-1-kinase for conversion of fructose-6phosphate to fructose-1,6-bisphosphate at the third step of the cellular glycolysis reaction. The decrease in the Fru2,6- $\mathrm{P}_{2}$ level induces the formation of fructose-6-phosphate. TIGAR causes a significant reduction in the cellular Fru2,6- $\mathrm{P}_{2}$ levels and thereby blocks glycolysis at this step. TIGAR directs the metabolism of cellular glucose through pentose phosphate pathway thus producing the redoxactive reactive oxygen species (ROS) quenching NADPH [15]. TIGAR is direct transcriptional target of p53 and p53 has two binding sites in the TIGAR promoter named BS1 and BS2. BS1 shows little binding affinity towards p53 and lies upstream the +1 transcription start site, whereas BS2 shows strong binding affinity towards p53 and lies in the first intron downstream the +1 transcription start site [15]. Since TIGAR activates the pentose-phosphate pathway and causes an increase in the NADPH generation, this causes an increase in cellular glutathione (GSH) levels, which acts as ROS scavengers. Bensaad et al ${ }^{12}$ reported that overexpression of TIGAR cDNA in cancer cells led to ROS quenching and protection from p53mediated apoptosis as a result of genotoxic stress and DNA-damage [16]. Further, it has been reported that 
TIGAR-mediated increase in the pentose-phosphatepathway also led to substantial increase in the cellular DNA repair [17]. Increase in the cellular NADPH levels blocks the apoptotic effector caspases like caspase-2 and caspase-9 [18], thus resulting in neutralization of p53 apoptotic response.

ROS, generated under conditions of genotoxicity and mitochondrial stress, transcriptionally activate p53, facilitate its nuclear entry, and inhibits p53 binding with MDM2 [19]. It appears that the sequence of cellular events involving activation of p53, TIGAR upregulation, inhibition of glycolysis, increase in pentose-phosphate pathway, generation of ROS scavenging GSH and NADPH are a part of the p53 feedback loop to neutralize ROS-induced cell death. Further, this pathway might help in DNA and cellular damage repair in cancer cells suffering from repairable dose of cellular/genotoxic insult [15]. Interestingly, the mechanism behind the choice made by $\mathrm{p} 53$ to drive cells for apoptosis or to facilitate cellular repair through TIGAR pathway is unknown. Collectively, these observations suggest that the effects of p53 on metabolism are responses to environmental conditions.

\section{ROLE OF P53 IN THE REGULATION OF OXIDATIVE PHOSPHORYLATION}

Oxidative phosphorylation (OXPHOS) is the mitochondrial pathway of energy generation which succeeds tricarboxylic acid (TCA) cycle to produce adenosine triphosphate (ATP) through electron transportcoupled OXPHOS [6]. p53 is now shown to directly regulate OXPHOS in mice and human cancer cell lines through transcriptional upregulation of its downstream gene synthesis of cytochrome $c$ oxidase (SCO2) [10]. p53 directly binds to $\mathrm{SCO} 2$ promoter and induces an increase in its mRNA and protein level. SCO2 is a COX assembly protein required for transfer of copper to the cytochrome $c$ oxidase (COX) complex. COX, the inner mitochondrial membrane protein comprises of thirteen subunits (three mitochondrial-encoded subunits and ten nuclear-encoded subunits). SCO proteins (SCO1 and SCO2) are part of the COX holo-enzymes and are required for transfer of copper from COX17 to COX [20]. SCO2 acts upstream of SCO1 in this pathway, and is indispensable for COX II synthesis [21, 22]. SCO1 and SCO2 gene mutations in humans results in poor formation of COX and $\mathrm{COX}$ deficiency. SCO2 mutations result in neonatal encephalocardiomyopathy, spinal muscular atrophy (SMA), neonatal hepatic failure, and fatal hypertrophic cardiomyopathy $[23,24]$. Most of the SCO2 patients carry an E140K missense mutation on one allele adjacent to the conserved $\mathrm{CxxxC}$ motif which regulates the efficiency of SCO2 to bind to copper and function as a redox protein [22].

$\mathrm{SCO} 2$ protein is regulated by $\mathrm{p} 53$ thus it can be postulated that $\mathrm{p} 53$ via SCO2 plays a major role in copper homeostasis. Copper is stored in the mitochondrial matrix space and mitochondrial inner membrane is impermeable to copper transport, thus copper-binding membrane proteins are indispensable to the transport of copper between the mitochondria and the cytoplasm. In fact, severe cellular copper deficiency is observed in patients with non-functional $\mathrm{SCO} 2$ protein and further wild-type SCO2 overexpression complements the copper-deficiency phenotype [25]. The transcriptional regulation of $\mathrm{SCO} 2$ by p53 might also be responsible for p53-mediated regulation of mitochondrial signals and cellular thiol-disulfide oxidoreductase reactions required for oxidation of the copper-binding cysteine amino acids in the mitochondrial proteins [22].

In human colon cancer cell lines, DLD1 and SW480, the overexpression of SCO2 protein increase OXPHOS even in presence of p53 mutations suggesting that p53mediated regulation of OXPHOS is via SCO2 [10]. In HCT116 human colon cancer cell line, deficiency in p53 causes low expression of SCO2, resulting in lower OXPHOS which is balanced by the increase in glycolysis [26]. This suggests that the downregulation of p53dependent regulation of $\mathrm{SCO} 2$ impairs the mitochondrial respiratory chain, causing a shifting of ATP production from OXPHOS to glycolysis.

\section{RELATIONSHIP BETWEEN TIGAR, SCO2 AND P53-MEDIATED EFFECTOR RESPONSES}

TIGAR suppresses glycolysis which generates necessary NADPH required for the OXPHOS. Thus synthesis of TIGAR should down-regulate OXPHOS, instead p53 transcriptionally synthesizes another gene $\mathrm{SCO} 2$ which up-regulates OXPHOS. It is understandable that in order to support p53 and SCO2-mediated increase in OXPHOS the cellular glycolytic levels must also be high. Thus p53 cannot transcriptionally regulate TIGAR and $\mathrm{SCO} 2$ at the same time and their regulation via p53 must be temporally segregated. It is logical to believe that p53 might upregulate either TIGAR or SCO2 at one point in time depending upon the intensity of the cellular and genotoxic stressors; however no data is available to support this hypothesis. On basis of the existing literature and the cellular outcomes observed upon upregulation of TIGAR and SCO2 in cancer cells, the cellular conditions which might lead to the synthesis of these genes can be predicted. Further, the individual role of TIGAR and $\mathrm{SCO} 2$ in assisting the tumor suppressor response of p53 can be hypothesized.

The effect of TIGAR on cell survival was proposed to be cell and context dependent [15]. Interestingly, the switch from $\mathrm{p} 53$-induced cell-cycle arrest to apoptosis following prolonged stress is associated with a decrease in expression of both TIGAR and $\mathrm{p} 21^{\mathrm{WAF} / \mathrm{CIP} 1}$, suggesting that the induction of the apoptotic response may reflect upon the loss of protection by these p53-inducible survival 
signals. TIGAR might be recruited by p53 to induce cellcycle arrest in cancer cells undergoing mild cellular and genotoxic stress. Most importantly TIGAR has the ability to reduce cellular ROS, which is necessary for the p53mediated apoptotic response. TIGAR lowers glycolysis and thus significantly reduces the cellular ATP level, which is crucial for cell division and other housekeeping activities. We predict that TIGAR falls into the group of genes that are activated by low levels of stress and plays a key role in the tumor-suppressor function of p53. p53 tumor suppressor provides an opportunity of survival and resurrection to the cancer cells which are suffering for repairable doses of cellular/genotoxic insult through upregulation of TIGAR protein. A model has been proposed which explains the putative mechanism of the p53-mediated transcriptional regulation of TIGAR in inducing the cell-cycle arrest response in cancer cells (Figure 1a).

$\mathrm{SCO} 2$, on the other hand, increases OXPHOS and supports cell division and most importantly increase the ATP supply to the cancer cells. It is a well-known fact that the cellular apoptosis is an ATP-dependent process [27]. Further, reactive oxygen species (ROS) is a toxic byproduct of the mitochondrial energy production pathway, oxidative phosphorylation (OXPHOS), in cancer cells [28]. Since p53 increases OXPHOS via SCO2, it is logical to assume that p53-mediated $\mathrm{SCO} 2$ upregulation will eventually lead to accumulation of cellular ROS. ROS plays a major role in the progressive accumulation of cellular and tissue damage in neoplastic cells [29]. Further ROS also provides an efficient pathway of eliminating cancerous cells through apoptosis [29]. In addition to the synthesis of ROS there might be other pathways which determine the SCO2- and p53-mediated apoptotic response in the cancer cells which are suffering for the non-repairable doses of cellular/genotoxic stress. A model has been proposed to elucidate the predicted mechanism of p53-mediated transcriptional regulation of SCO2 gene in cancer cells (Figure 1b). It has become clear that in addition to the regulation of cellular metabolism, the p53- mediated transcriptional regulation of TIGAR and SCO2 is another tool in the armory of p53 to choose and protect cells which are capable of repair and further to effectively drive the non-repairable cells towards cellular apoptosis.

\section{ROLE OF P53 IN METABOLISM AND AGING}

The metabolic rate of organisms is related with their aging process [30]. Aging is dependent and proportional to the generation of ROS, a byproduct of cellular metabolism, which attack cell constituents and cause damage to cellular structures, and ROS is a by-product of metabolic reactions. ROS can induce apoptosis in cancer cells [19] thus cancer cells try and neutralize cellular oxidative stress via activation and upregulation of metabolic machinery involved in glycolysis. The crucial steps of this metabolic response against ROS production involves activation of the (i) pentose phosphate pathway (PPP), which regulates the redox status via the NADP+/NADPH ratio and (ii) glutathione system [7, 31].

Both anaerobic and aerobic glycolysis forms are high in cancer cells [8]. p53 is also now linked to regulate cellular aging through its newly found role in cellular metabolism. In cancer cells, p53-signaling molecule AMPK acts as an energy sensor and increases glycolysis $[32,33]$. AMPK can also activate the tumor suppressor p53 in a feed-back loop, thus promoting cellular survival and aging [34]. Recent studies by Kawauchi et al. [35, $36]$ have revealed that increased glycolysis can enhance the O-glycosylation of IKK $\beta$ that subsequently triggers the $\mathrm{NF}-\kappa \mathrm{B}$ signaling. Growing literature shows that the IKK/ $\mathrm{NF}-\kappa \mathrm{B}$ signaling pathway is involved in the carcinogenesis [37-39] but many observations also demonstrate that NF$\kappa \mathrm{B}$ system is activated during the aging process [40]. These observations refer to the fundamental role of glycolysis in cancer cells but it raises the question of whether p53 and the glycolytic flux can also regulate NF- $\kappa$ B signaling during the aging process. Interestingly, Kawauchi et al.
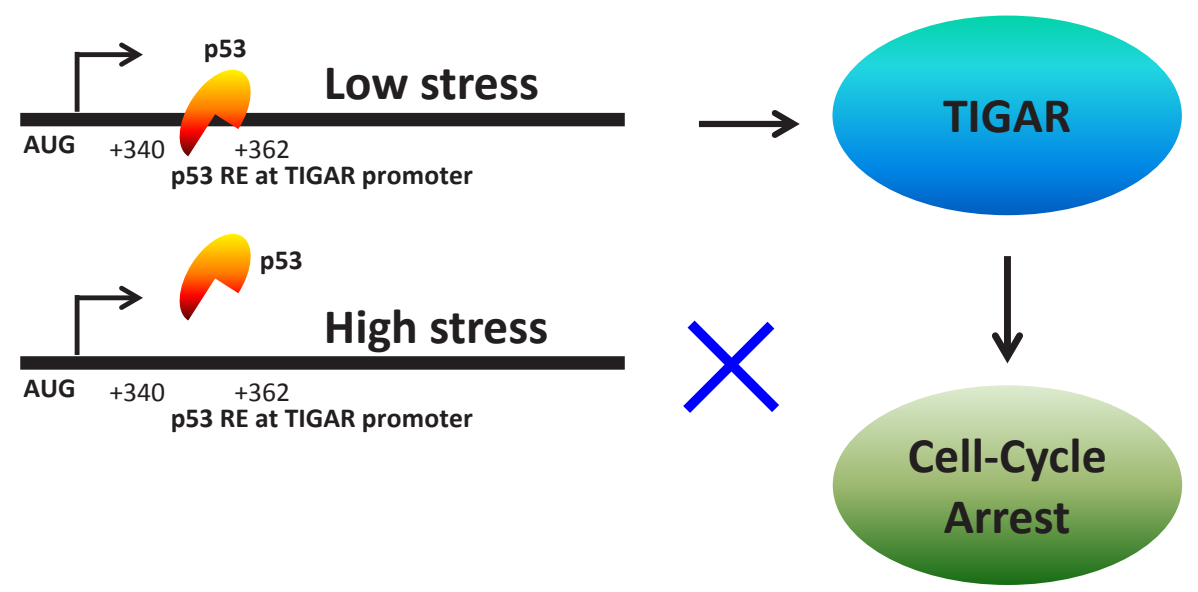

Figure 1a: A model depicting the mechanism of p53-mediated regulation of TIGAR gene in cancer cells. 
[35] observed that the glycolysis-dependent activation of $\mathrm{NF}-\kappa \mathrm{B}$ signaling is regulated by tumor suppressor $\mathrm{p} 53$ oncogene.

Since p53 has a profound effect on metabolism and it increases aerobic metabolism and inhibits glycolysis [41]. The O-glycosylation of NF- $\mathrm{KB}$ at its $\mathrm{Ser} / \mathrm{Thr}$ residues via HBP pathway has revealed the role of $\mathrm{p} 53$, $\mathrm{NF}-\kappa \mathrm{B}$ and metabolism in the process of aging $[35,36$, 42]. p53 is now known to negatively regulate the IKK/ NF- $\mathrm{kB}$ signaling through $\mathrm{p} 53$-dependent regulation of glycolysis via TIGAR. High glucose levels increase O-GlcNAc of IKK $\beta$ at its Ser733 residue, which is an inactivating phosphorylation site of the enzyme $[35,36]$. High glucose levels can also increase the O-GlcNAc modification of $\mathrm{p} 65$, the trans-activating component of the NF- $\kappa$ B complex [43]. O-GlcNAc-p65 does not bind to its inhibitory protein I $\kappa-\mathrm{B} \alpha$ and thus increases

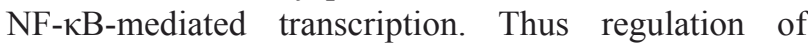
cellular glucose levels and glycolysis by p53 controls the NF- $\mathrm{kB}$-mediated transcription. The p53-mediated regulation of TIGAR seems to function in another feedback loop since O-GlcNAc-p53 is protected from its ubiquitination-mediated degradation [44]. p53 deletions and mutations will result in transcriptional inhibition at TIGAR promoter, thus an increases the glycolysis and the transcriptionally active O-GlcNAc- NF- $\mathrm{KB}$ thus the development and progression of cancer [39]. It is logical to assume that $\mathrm{p} 53$ might suppress the NF- $\mathrm{KB}$ signaling via the inhibition of glycolysis through regulation of TIGAR protein. NF- $\mathrm{KB}$ signaling and glycolysis are involved in pre-mature aging. The anti-aging proteins and the p53 c-terminus de-acetylases Sirtuin family of proteins, SIRT1 and SIRT6, are powerful inhibitors of $\mathrm{NF}-\kappa \mathrm{B}$ signaling as well. It is established that p53 lies at the nexus of the phenomena of aging and cancer [45, 46]. p53 stabilization in mouse models have resulted in resistance to cancer in combination with the development of the signs of pre-mature aging [47]. P53 transcriptional activity also decreases with increasing age of animals [48].
It is believed that decrease in p53 transcriptional activity in mammalian systems will lead to increase in glycolysis and decrease in OXPHOS, ultimately resulting in a strong relation between metabolism and aging.

\section{P53 AT THE NEXUS OF CELLULAR AGING AND SENESCENCE}

Cellular senescence is a complexity of aging and cancer biology. As malignant tumors can culminate individuals in life-termination, evolution has provided multicellular organisms with an acquisition of distinctive safety device, cellular senescence, to circumvent the development. Cellular senescence, a state of irreversible growth arrest and cellular aging, an increase in the probability of death over survival, both can be triggered by multiple mechanisms. Eukaryotic cells have carefully devised these checkpoints to limit oncogenic cellular proliferation. Senescent cells may remain viable and quiescent in culture conditions and in the organisms [49] or may be cleared by the phagocytic machinery [50]. Senescence and aging are linked since aging is accompanied by increase in the volume of senescent cells and decrease in the division/regeneration potential of the stem-cell pool [51]. The telomere clock is one connecting link between senescence and aging. Telomeremediated protection against cancer induces senescence and/or apoptosis $[52,53]$. Telomere-induced senescence is now an established anti-neoplastic mechanism [54]. In humans, an inverse correlation between telomere length and cellular aging and between telomere length and aging related diseases is now well established [55, 56]. Factors which are known to decrease longevity, are known to decrease telomerase activity and telomere length $[57,58]$. Furthermore, human premature aging syndromes, like dyskeratosis congenita and aplastic anemia, are linked with telomere shortening [59]. Further reinforcing the link between the telomere clock and

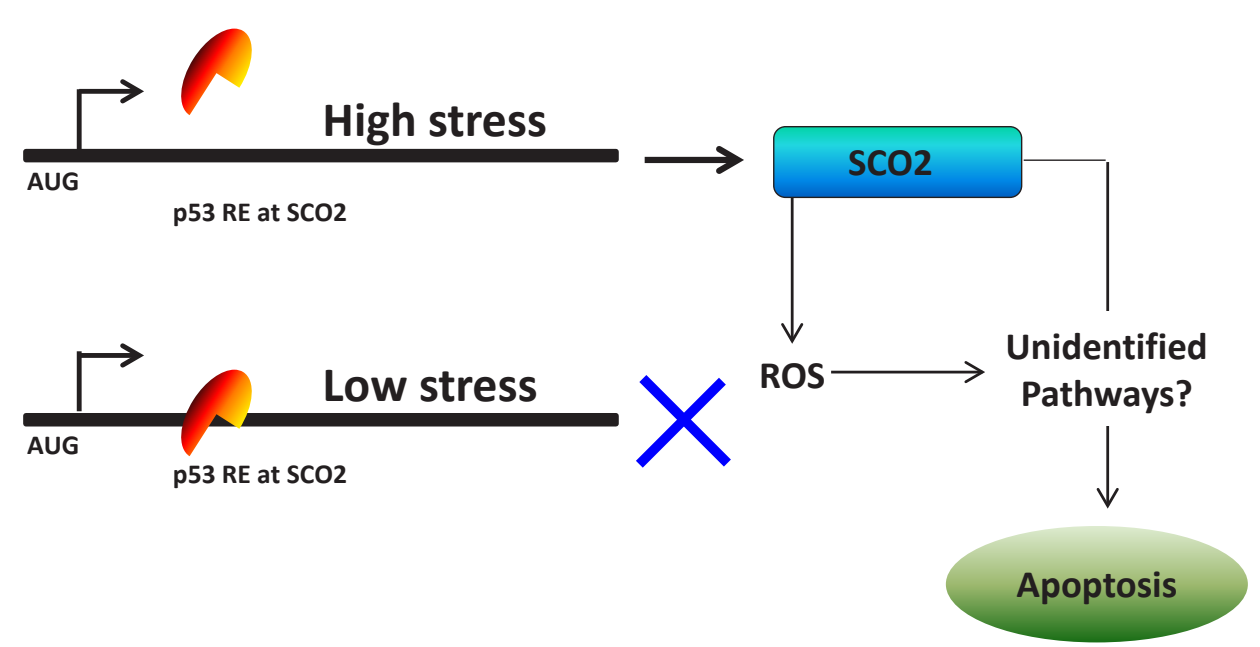

Figure 1b: A model depicting the mechanism of p53-mediated regulation of SCO2 gene in cancer cells. 
aging is the observation that mice deficient in telomerase activity have short telomeres and age prematurely [60, 61]. Remarkably, even the first generation of telomerasedeficient mice already has a shortened lifespan, which becomes shorter and shorter in subsequent generations [62]. Moreover, telomeres become measurably shorter in mice, particularly at very old ages [63]. Finally, mice overexpressing telomerase are prone to developing tumors $[64,65]$, thus precluding direct demonstration of lifespan extension by telomerase; nonetheless, an increase in the lifespan of those few telomerase transgenic mice that do not develop cancer has been observed [66]. p53 plays a critical role in maintaining telomere stability [67]. p21Cip1, a direct transcriptional target of p53, has been shown to be relevant in the signaling of critically short telomeres that leads to aging [68]. p21Cip1 gene deletion in mice models has been shown to increase longevity of telomerase-deficient mice. Further no tumor formation was observed which was paradoxical to the effects observed in p53-deficient mice [69]. This data further confirmed that p53/p21Cip1-dependent senescence specifically induces the pro-aging effect of short telomeres. It is now believed that $\mathrm{p} 53$-mediates both the pro-aging function of telomere shortening [70].

The role of p53 in senescence and aging is not clearly established. Recently several transcription factors have been identified which can both inhibit senescence and induce epithelial-mesenchymal transition (EMT) thereby increasing the probability of cancer development [71]. Mice programmed to constitutively overexpress transcriptionally active mutant p53 have minimal probability of tumor development than wild-type mice. However, such programmed mice show signs of premature aging [72, 73]. Interestingly, mice with increased wild-type p53 activity do not exhibit premature aging. Super-p53 mice, carrying an extra copy of the entire p53 gene, show minimal probability of tumor development teamed up with a display of normal longevity [74]. Extra dose of $\mathrm{p} 53$ also increases the antioxidant function of p53 $[16,75]$. The conclusion from these observations can be made which is suggestive of the fact that the main role of p53 is to eliminate damaged cells, either by triggering their self-destruction (via apoptosis) or by stalling them out of the proliferative pool (via senescence). During repairable doses of cellular insult, p53 induces the cell-repair pathways and thus activates the anti-aging program which compensates for the pro-aging response evoked by p53-mediated apoptosis. Exogenous addition of p53 copy can cause reversible cell-cycle arrest and/or irreversible senescence. Nutlin-3a (a small molecule that activates p53 without causing DNA damage), is unique in inducing senescence without making the cells quiescent. Interestingly, nutlin-3a inhibits the mTOR (mammalian target of rapamycin) pathway, a known member of the senescence program. It is recently shown that the negative regulators of the mTOR signaling, partially converts quiescence into senescence in the nutlin-treated cells. The mTOR pathway thus is one of the determining factors in facilitating the choice of $\mathrm{p} 53$ between the senescence and quiescence program in the p53-arrested cells [76, 77]. Further it has been shown that the p53-induced quiescence is in fact a result of suppression of senescence by $\mathrm{p} 53$. In cancer cells arrested with overexpression of $\mathrm{p} 21$, the addition of p53 converted senescence into quiescence and this suppression of senescence by p53 was dependent on p53-transcriptional activity. Thus, in spite of its ability to induce cell-cycle arrest, p53 can act as a suppressor of cellular senescence $[33,78]$. p53 can promote or retard aging, depending on the context of its regulation and activity. p53 can regulate both pro-aging and pro-longevity effects by either inducing excessive apoptosis/cellular senescence or by eliminating damaged or dysfunctional cells via apoptosis/senescence [79]. p53 also transcriptionally regulates insulin/insulin-like growth factor (IGF)-1 involved in the IIS pathway. IIS and one of its major intracellular targets, the mTOR pathway, drive aging in mice [80]. In general, high IIS/mTOR activity is associated with cell proliferation, growth and aging, whereas low IIS/mTOR activity is associated with somatic maintenance and longevity. In addition, p53 is regulated, directly and indirectly (through MDM2), by another major component of IIS signaling, the PKB/Akt kinase [81]. $\mathrm{PKB} / \mathrm{Akt}$ signaling in turn is also both pro-aging (through the NF-kB transcription factor) and pro-longevity (through FOXO transcription factors) [82]. p53 transcriptional activity depends mainly on post-translational modifications and protein/protein interaction [83]. Even though cancer cells have partially lost the capacity to signal senescence or apoptosis, these responses can conceivably be engaged by exogenous agents like p53-activating drugs and p53modulating molecular chaperones [84-86].

The p53-dependent association between cellular senescence and organismal aging is highly suggestive of a causal link between these two processes. The cellular factors which trigger senescence also trigger apoptosis and cell-cycle arrest which makes it challenging to distinguish between the role of these three processes in aging [87]. It is interesting to observe that cancer is more frequent in old age human beings. The simplest explanation for this is that old organisms have accumulated more genetic and epigenetic aberrations than young organisms, but this does not say anything about the intrinsic susceptibility (that is, apart from the accumulation of mutations) of young and old organisms to develop cancer. Higher incidence of cancer at old ages simply reflects the time needed for the accumulation of oncogenic mutations. However, one must not neglect that with higher age there is a convenient environment for cancer growth. Great progress has been made in the last few years in understanding how cells limit their proliferative potential and in linking these mechanisms to cancer protection and aging. Future research will clarify whether therapies that induce 
senescence are useful for cancer treatment, and determine their effect on aging. Conversely, treatments that inhibit senescence in healthy individuals might slow aspects of aging.

\section{CONCLUSION AND FUTURE DIRECTIONS}

In summary, p53's myriad of functions is beyond the tumor suppressor roles of being a protein involved in cell-cycle arrest, apoptosis and DNA-repair. However, the regulation of p53 has turned out to be highly complex and context-dependent. For instance, emerging results suggest that p53 has both nuclear and cytoplasmic functions [88] which may explain some of the controversial observations in transgenic models. p53 is now known to regulate stress-induced transcriptional programs that manipulate the energy metabolism of cancer cells in order to facilitate the tumor suppressor role of $\mathrm{p} 53$. The mechanisms regulating the opposite cell fates in cancer development and organism aging have been exciting cell biological topics for years. In particular, a lot of research effort has been focused on the role of p53 in the regulation of longevity [89, 90]. Furthermore, the role of p53 in the regulation of energy metabolism is a promising research field [41] which can provide some explanations to the puzzles of cancer and aging. It is established that energy metabolism is crucial for ever-proliferating cancer cells for their continued growth and survival. The activation of p53 to alternatively regulate the two most important aspects of metabolism, glycolysis via TIGAR and OXPHOS via SCO2 reveals that there are functions for p53 in the regulation of other metabolic diseases. Interestingly, how p53 can antagonistically regulate two crucial steps of the respiration cycle and the relation of this regulation with the well-defined tumor suppressor role of p53 needs to be elucidated.

\section{REFERENCES}

1. Vogelstein B, Lane D, Levine AJ. Surfing the p53 network. Nature. 2000; 408:307-310.

2. Liebermann DA, Hoffman B, Vesely D. p53 induced growth arrest versus apoptosis and its modulation by survival cytokines. Cell cycle. 2007; 6:166-170.

3. Skinner HD, Sandulache VC, Ow TJ, Meyn RE, Yordy JS, Beadle BM, Fitzgerald AL, Giri U, Ang KK, Myers JN. TP53 disruptive mutations lead to head and neck cancer treatment failure through inhibition of radiation-induced senescence. Clinical cancer research : an official journal of the American Association for Cancer Research. 2011.

4. Levine AJ. p53, the cellular gatekeeper for growth and division. Cell. 1997; 88:323-331.

5. Xiao J, Lin H, Luo X, Wang Z. miR-605 joins p53 network to form a p53:miR-605:Mdm2 positive feedback loop in response to stress. The EMBO journal. 2011; 30:5021.

6. Jones RG, Thompson CB. Tumor suppressors and cell metabolism: a recipe for cancer growth. Genes Dev. 2009; 23:537-548.

7. Pedersen PL. Warburg, me and Hexokinase 2: Multiple discoveries of key molecular events underlying one of cancers' most common phenotypes, the "Warburg Effect", i.e., elevated glycolysis in the presence of oxygen. J Bioenerg Biomembr. 2007; 39:211-222.

8. Yeung SJ, Pan J, Lee MH. Roles of p53, MYC and HIF-1 in regulating glycolysis - the seventh hallmark of cancer. Cell Mol Life Sci. 2008; 65:3981-3999.

9. Bensaad K, Vousden KH. p53: new roles in metabolism. Trends Cell Biol. 2007; 17:286-291.

10. Matoba S, Kang JG, Patino WD, Wragg A, Boehm M, Gavrilova O, Hurley PJ, Bunz F, Hwang PM. p53 regulates mitochondrial respiration. Science. 2006; 312:1650-1653.

11. Olovnikov IA, Kravchenko JE, Chumakov PM. Homeostatic functions of the p53 tumor suppressor: regulation of energy metabolism and antioxidant defense. Semin Cancer Biol. 2009; 19:32-41.

12. Salminen A, Kaarniranta K. Insulin/IGF-1 paradox of aging: regulation via AKT/IKK/NF-kappaB signaling. Cell Signal. 2010; 22:573-577.

13. Semenza GL. Regulation of cancer cell metabolism by hypoxia-inducible factor 1. Semin Cancer Biol. 2009; 19:12-16.

14. Brahimi-Horn MC, Chiche J, Pouyssegur J. Hypoxia signalling controls metabolic demand. Curr Opin Cell Biol. 2007; 19:223-229.

15. Bensaad K, Tsuruta A, Selak MA, Vidal MN, Nakano K, Bartrons R, Gottlieb E, Vousden KH. TIGAR, a p53inducible regulator of glycolysis and apoptosis. Cell. 2006; 126:107-120.

16. Sablina AA, Budanov AV, Ilyinskaya GV, Agapova LS, Kravchenko JE, Chumakov PM. The antioxidant function of the p53 tumor suppressor. Nat Med. 2005; 11:1306-1313.

17. Zhang YM, Liu JK, Wong TY. The DNA excision repair system of the highly radioresistant bacterium Deinococcus radiodurans is facilitated by the pentose phosphate pathway. Mol Microbiol. 2003; 48:1317-1323.

18. Nutt LK, Margolis SS, Jensen M, Herman CE, Dunphy WG, Rathmell JC, Kornbluth S. Metabolic regulation of oocyte cell death through the CaMKII-mediated phosphorylation of caspase-2. Cell. 2005; 123:89-103.

19. Liu B, Chen Y, St Clair DK. ROS and p53: a versatile partnership. Free Radic Biol Med. 2008; 44:1529-1535.

20. Glerum DM, Shtanko A, Tzagoloff A. SCO1 and SCO2 act as high copy suppressors of a mitochondrial copper recruitment defect in Saccharomyces cerevisiae. J Biol Chem. 1996; 271:20531-20535.

21. Leary SC, Kaufman BA, Pellecchia G, Guercin GH, Mattman A, Jaksch M, Shoubridge EA. Human SCO1 and $\mathrm{SCO} 2$ have independent, cooperative functions in copper 
delivery to cytochrome c oxidase. Hum Mol Genet. 2004; 13:1839-1848.

22. Leary SC, Sasarman F, Nishimura T, Shoubridge EA. Human SCO2 is required for the synthesis of CO II and as a thiol-disulphide oxidoreductase for SCO1. Hum Mol Genet. 2009; 18:2230-2240.

23. Salviati L, Sacconi S, Rasalan MM, Kronn DF, Braun A, Canoll P, Davidson M, Shanske S, Bonilla E, Hays AP, Schon EA, DiMauro S. Cytochrome c oxidase deficiency due to a novel SCO2 mutation mimics Werdnig-Hoffmann disease. Arch Neurol. 2002; 59:862-865.

24. Tarnopolsky MA, Bourgeois JM, Fu MH, Kataeva G, Shah J, Simon DK, Mahoney D, Johns D, MacKay N, Robinson BH. Novel SCO2 mutation (G1521A) presenting as a spinal muscular atrophy type I phenotype. Am J Med Genet A. 2004; 125A:310-314.

25. Stiburek L, Vesela K, Hansikova H, Hulkova H, Zeman J. Loss of function of Scol and its interaction with cytochrome c oxidase. Am J Physiol Cell Physiol. 2009; 296:C1218-1226.

26. Ma W, Sung HJ, Park JY, Matoba S, Hwang PM. A pivotal role for p53: balancing aerobic respiration and glycolysis. J Bioenerg Biomembr. 2007; 39:243-246.

27. Zamaraeva MV, Sabirov RZ, Maeno E, Ando-Akatsuka Y, Bessonova SV, Okada Y. Cells die with increased cytosolic ATP during apoptosis: a bioluminescence study with intracellular luciferase. Cell Death Differ. 2005; 12:13901397.

28. Kokoszka JE, Coskun P, Esposito LA, Wallace DC. Increased mitochondrial oxidative stress in the Sod2 (+/-) mouse results in the age-related decline of mitochondrial function culminating in increased apoptosis. Proc Natl Acad Sci U S A. 2001; 98:2278-2283.

29. Vahsen N, Cande C, Briere JJ, Benit P, Joza N, Larochette $\mathrm{N}$, Mastroberardino PG, Pequignot MO, Casares N, Lazar V, Feraud O, Debili N, Wissing S, Engelhardt S, Madeo F, Piacentini $\mathrm{M}$ et al. AIF deficiency compromises oxidative phosphorylation. EMBO J. 2004; 23:4679-4689.

30. A.J H. The links between membrane composition, metabolic rate and lifespan. Comparative Biochemistry and Physiology - Part A: Molecular \&amp; Integrative Physiology. 2008; 150:196-203.

31. Almeida A, Moncada S, Bolanos JP. Nitric oxide switches on glycolysis through the AMP protein kinase and 6-phosphofructo-2-kinase pathway. Nat Cell Biol. 2004; 6:45-51.

32. Towler MC, Hardie DG. AMP-activated protein kinase in metabolic control and insulin signaling. Circ Res. 2007; 100:328-341.

33. Demidenko ZN, Korotchkina LG, Gudkov AV, Blagosklonny MV. Paradoxical suppression of cellular senescence by p53. Proc Natl Acad Sci U S A. 2010; 107:9660-9664.

34. Jones RG, Plas DR, Kubek S, Buzzai M, Mu J, Xu Y,
Birnbaum MJ, Thompson CB. AMP-activated protein kinase induces a p53-dependent metabolic checkpoint. Mol Cell. 2005; 18:283-293.

35. Kawauchi K, Araki K, Tobiume K, Tanaka N. p53 regulates glucose metabolism through an IKK-NF-kappaB pathway and inhibits cell transformation. Nat Cell Biol. 2008; 10:611-618.

36. Kawauchi K, Araki K, Tobiume K, Tanaka N. Loss of p53 enhances catalytic activity of IKKbeta through O-linked beta-N-acetyl glucosamine modification. Proc Natl Acad Sci U S A. 2009; 106:3431-3436.

37. Li Q, Withoff S, Verma IM. Inflammation-associated cancer: NF-kappaB is the lynchpin. Trends Immunol. 2005; 26:318-325.

38. Perkins ND. NF-kappaB: tumor promoter or suppressor? Trends Cell Biol. 2004; 14:64-69.

39. Karin M. The IkappaB kinase - a bridge between inflammation and cancer. Cell Res. 2008; 18:334-342.

40. Salminen A, Kaarniranta K. NF-kappaB signaling in the aging process. J Clin Immunol. 2009; 29:397-405.

41. Vousden KH, Ryan KM. p53 and metabolism. Nat Rev Cancer. 2009; 9:691-700.

42. Zachara NE, Hart GW. Cell signaling, the essential role of O-GlcNAc! Biochim Biophys Acta. 2006; 1761:599-617.

43. Yang WH, Park SY, Nam HW, Kim do H, Kang JG, Kang ES, Kim YS, Lee HC, Kim KS, Cho JW. NFkappaB activation is associated with its O-GlcNAcylation state under hyperglycemic conditions. Proc Natl Acad Sci U S A. 2008; 105:17345-17350.

44. Yang WH, Kim JE, Nam HW, Ju JW, Kim HS, Kim YS, Cho JW. Modification of p53 with O-linked $\mathrm{N}$-acetylglucosamine regulates p53 activity and stability. Nat Cell Biol. 2006; 8:1074-1083.

45. Finkel T, Serrano M, Blasco MA. The common biology of cancer and ageing. Nature. 2007; 448:767-774.

46. Papazoglu C, Mills AA. p53: at the crossroad between cancer and ageing. J Pathol. 2007; 211:124-133.

47. Moore L, Lu X, Ghebranious N, Tyner S, Donehower LA. Aging-associated truncated form of p53 interacts with wildtype p53 and alters p53 stability, localization, and activity. Mech Ageing Dev. 2007; 128:717-730.

48. Feng Z, Hu W, Teresky AK, Hernando E, Cordon-Cardo $\mathrm{C}$, Levine AJ. Declining p53 function in the aging process: a possible mechanism for the increased tumor incidence in older populations. Proc Natl Acad Sci U S A. 2007; 104:16633-16638.

49. Michaloglou C, Vredeveld LC, Soengas MS, Denoyelle C, Kuilman T, van der Horst CM, Majoor DM, Shay JW, Mooi WJ, Peeper DS. BRAFE600-associated senescence-like cell cycle arrest of human naevi. Nature. 2005; 436:720-724.

50. Xue W, Zender L, Miething C, Dickins RA, Hernando E, Krizhanovsky V, Cordon-Cardo C, Lowe SW. Senescence and tumour clearance is triggered by p53 restoration in 
murine liver carcinomas. Nature. 2007; 445:656-660.

51. Dimri GP, Lee X, Basile G, Acosta M, Scott G, Roskelley C, Medrano EE, Linskens M, Rubelj I, Pereira-Smith O, et al. A biomarker that identifies senescent human cells in culture and in aging skin in vivo. Proc Natl Acad Sci U S A. 1995; 92:9363-9367.

52. Kelland LR. Overcoming the immortality of tumour cells by telomere and telomerase based cancer therapeutics--current status and future prospects. Eur J Cancer. 2005; 41:971-979.

53. Shammas MA, Koley H, Batchu RB, Bertheau RC, Protopopov A, Munshi NC, Goyal RK. Telomerase inhibition by siRNA causes senescence and apoptosis in Barrett's adenocarcinoma cells: mechanism and therapeutic potential. Mol Cancer. 2005; 4:24.

54. Feldser DM, Greider CW. Short telomeres limit tumor progression in vivo by inducing senescence. Cancer Cell. 2007; 11:461-469.

55. Canela A, Vera E, Klatt P, Blasco MA. High-throughput telomere length quantification by FISH and its application to human population studies. Proc Natl Acad Sci U S A. 2007; 104:5300-5305.

56. Ogami M, Ikura Y, Ohsawa M, Matsuo T, Kayo S, Yoshimi N, Hai E, Shirai N, Ehara S, Komatsu R, Naruko T, Ueda $\mathrm{M}$. Telomere shortening in human coronary artery diseases. Arterioscler Thromb Vasc Biol. 2004; 24:546-550.

57. Epel ES, Blackburn EH, Lin J, Dhabhar FS, Adler NE, Morrow JD, Cawthon RM. Accelerated telomere shortening in response to life stress. Proc Natl Acad Sci U S A. 2004; 101:17312-17315.

58. Valdes AM, Andrew T, Gardner JP, Kimura M, Oelsner E, Cherkas LF, Aviv A, Spector TD. Obesity, cigarette smoking, and telomere length in women. Lancet. 2005; 366:662-664.

59. Mason PJ, Bessler M. Heterozygous telomerase deficiency in mouse and man: when less is definitely not more. Cell Cycle. 2004; 3:1127-1129.

60. Blasco MA, Lee HW, Hande MP, Samper E, Lansdorp PM, DePinho RA, Greider CW. Telomere shortening and tumor formation by mouse cells lacking telomerase RNA. Cell. 1997; 91:25-34.

61. Lee HW, Blasco MA, Gottlieb GJ, Horner JW, 2nd, Greider CW, DePinho RA. Essential role of mouse telomerase in highly proliferative organs. Nature. 1998; 392:569-574.

62. Garcia-Cao I, Garcia-Cao M, Tomas-Loba A, MartinCaballero J, Flores JM, Klatt P, Blasco MA, Serrano M. Increased $\mathrm{p} 53$ activity does not accelerate telomere-driven ageing. EMBO Rep. 2006; 7:546-552.

63. Coviello-McLaughlin GM, Prowse KR. Telomere length regulation during postnatal development and ageing in Mus spretus. Nucleic Acids Res. 1997; 25:3051-3058.

64. Canela A, Martin-Caballero J, Flores JM, Blasco MA. Constitutive expression of tert in thymocytes leads to increased incidence and dissemination of T-cell lymphoma in Lck-Tert mice. Mol Cell Biol. 2004; 24:4275-4293.

65. Gonzalez-Suarez E, Samper E, Ramirez A, Flores JM, Martin-Caballero J, Jorcano JL, Blasco MA. Increased epidermal tumors and increased skin wound healing in transgenic mice overexpressing the catalytic subunit of telomerase, mTERT, in basal keratinocytes. EMBO J. 2001; 20:2619-2630.

66. Gonzalez-Suarez E, Geserick C, Flores JM, Blasco MA. Antagonistic effects of telomerase on cancer and aging in K5-mTert transgenic mice. Oncogene. 2005; 24:2256-2270.

67. Gu J, Spitz MR, Zhao H, Lin J, Grossman HB, Dinney CP, $\mathrm{Wu} \mathrm{X}$. Roles of tumor suppressor and telomere maintenance genes in cancer and aging--an epidemiological study. Carcinogenesis. 2005; 26:1741-1747.

68. Choudhury AR, Ju Z, Djojosubroto MW, Schienke A, Lechel A, Schaetzlein S, Jiang H, Stepczynska A, Wang C, Buer J, Lee HW, von Zglinicki T, Ganser A, Schirmacher P, Nakauchi H, Rudolph KL. Cdknla deletion improves stem cell function and lifespan of mice with dysfunctional telomeres without accelerating cancer formation. Nat Genet. 2007; 39:99-105.

69. Chin L, Artandi SE, Shen Q, Tam A, Lee SL, Gottlieb GJ, Greider CW, DePinho RA. p53 deficiency rescues the adverse effects of telomere loss and cooperates with telomere dysfunction to accelerate carcinogenesis. Cell. 1999; 97:527-538.

70. Collado M, Blasco MA, Serrano M. Cellular senescence in cancer and aging. Cell. 2007; 130:223-233.

71. Smit MA, Peeper DS. Epithelial-mesenchymal transition and senescence: two cancer-related processes are crossing paths. Aging (Albany NY). 2010; 2:735-741.

72. Maier B, Gluba W, Bernier B, Turner T, Mohammad K, Guise T, Sutherland A, Thorner M, Scrable H. Modulation of mammalian life span by the short isoform of p53. Genes Dev. 2004; 18:306-319.

73. Tyner SD, Venkatachalam S, Choi J, Jones S, Ghebranious N, Igelmann H, Lu X, Soron G, Cooper B, Brayton C, Hee Park S, Thompson T, Karsenty G, Bradley A, Donehower LA. p53 mutant mice that display early ageing-associated phenotypes. Nature. 2002; 415:45-53.

74. Garcia-Cao I, Garcia-Cao M, Martin-Caballero J, Criado LM, Klatt P, Flores JM, Weill JC, Blasco MA, Serrano M. "Super p53" mice exhibit enhanced DNA damage response, are tumor resistant and age normally. EMBO J. 2002; 21:6225-6235.

75. Vigneron A, Vousden KH. p53, ROS and senescence in the control of aging. Aging (Albany NY). 2010; 2:471-474.

76. Korotchkina LG, Leontieva OV, Bukreeva EI, Demidenko ZN, Gudkov AV, Blagosklonny MV. The choice between p53-induced senescence and quiescence is determined in part by the mTOR pathway. Aging (Albany NY). 2010; 2:344-352.

77. Galluzzi L, Kepp O, Kroemer G. TP53 and MTOR crosstalk to regulate cellular senescence. Aging (Albany NY). 2010; 
2:535-537.

78. Maki CG. Decision-making by $\mathrm{p} 53$ and mTOR. Aging (Albany NY). 2010; 2:324-326.

79. de Keizer PL, Laberge RM, Campisi J. p53: Pro-aging or pro-longevity? Aging (Albany NY). 2010; 2:377-379.

80. Kenyon CJ. The genetics of ageing. Nature. 2010; 464:504512.

81. Mayo LD, Donner DB. The PTEN, Mdm2, p53 tumor suppressor-oncoprotein network. Trends Biochem Sci. 2002; 27:462-467.

82. Salminen A, Kaarniranta K. Glycolysis links p53 function with NF-kappaB signaling: impact on cancer and aging process. J Cell Physiol. 2010; 224:1-6.

83. Stanga S, Lanni C, Govoni S, Uberti D, D’Orazi G, Racchi M. Unfolded p53 in the pathogenesis of Alzheimer's disease: is HIPK2 the link? Aging (Albany NY). 2010; 2:545-554.

84. Gogna R, Madan E, Keppler B, Pati U. Gallium compound $\mathrm{GaQ}(3)$-induced $\mathrm{Ca}(2+)$ signaling triggers p53-dependent and independent apoptosis in cancer cells. Br J Pharmacol. 2011.

85. Gogna R, Madan E, Kuppusamy P, Pati U. Chaperoning of Mt p53 by Wt $\mathrm{p} 53$ causes hypoxic tumor regression. J Biol Chem. 2011.

86. Gogna R, Madan E, Kuppusamy P, Pati U. ROS-mediated p53 core-domain modifications determine apoptotic or necrotic death in cancer cells. Antioxid Redox Signal. 2011.

87. Poyurovsky MV, Prives C. P53 and aging: A fresh look at an old paradigm. Aging (Albany NY). 2010; 2:380-382.

88. Green DR, Kroemer G. Cytoplasmic functions of the tumour suppressor p53. Nature. 2009; 458:1127-1130.

89. Campisi J. Senescent cells, tumor suppression, and organismal aging: good citizens, bad neighbors. Cell. 2005; 120:513-522.

90. Rodier F, Campisi J, Bhaumik D. Two faces of p53: aging and tumor suppression. Nucleic Acids Res. 2007; 35:74757484. 